\title{
Growth, sporulation and toxin production by Bacillus thuringiensis isolates in media based on mustard-seed meal
}

\author{
Mohammad Hasibul Hasan, Asma Akter, Mohammad Ilias, Shakila N Khan, M Mozammel Hoq* \\ Department of Microbiology, University of Dhaka, Dhaka-1000, Bangladesh.
}

(Received 2 December 2010 ; Accepted 5 February 2011)

\begin{abstract}
This study was aimed at the large scale production and application of Bacillus thuringiensis (Bt) biopesticide in Bangladesh agriculture from locally available cheap raw materials. B. thuringiensis subsp. kurstaki HD-73 (reference strain) and two other indigenous isolates of $B$. thuringiensis namely Bt-Soil-47 and Bt-Insect-1i demonstrated satisfactory growth of sporulation and endotoxin production in a medium prepared from de-fatted mustard-seed meal (oil cake) as carbon and nitrogen sources at $30^{\circ} \mathrm{C}$. A correlation of growth, sporulation and endotoxin production pattern was obtained through the systematic study over the period of $72 \mathbf{~ h}$. Time course study of the growth of all three $B t$ isolates demonstrated similar pattern; however, spore-crystal complex formation of the indigenous Bt isolates was different with respect to the reference strain. The two indigenous isolates formed the maximum sporecrystal complex at $36 \mathrm{~h}$, whereas the reference strain did the same at $66 \mathrm{~h}$. Hence, the productivity of endotoxin formation of the indigenous isolates, $34.30 \times 10^{-3}$ and $37.50 \times 10^{-3} \mathrm{~g} / \mathrm{L} / \mathrm{h}$ respectively, were higher than that of the reference strain $\left(21.37 \times 10^{-3} \mathrm{~g} / \mathrm{L} / \mathrm{h}\right)$. Spore-crystal complex of the bacilli was recovered as dry powder which can be applied suitably in field to test their insecticidal activity. Molecular size of endotoxin of the isolates analyzed by SDS-PAGE resembled the typical sizes of the $\delta$-endotoxin of Bacillus thuringiensis.
\end{abstract}

Keywords: Bacillus thuringiensis, spore-crystal complex, $\delta$-endotoxin.

\section{Introduction}

The competition for crops between human and insects is as old as agriculture. The use of chemical substances to control pests was started in the mid-1800s. In past, certain inorganic and organic compounds, including organochlorides, organophosphates, carbamatespyrethroids and formamides were used as insecticides. Because of the special properties of these chemicals, such as long residual action and toxicity to a wide spectrum of organisms, they have been being used for a long time. However, using such chemicals may cause many environmental problems; for example, insect resistance, toxicity to humans, and to beneficial insects ${ }^{1}$.

The control of pest populations by using insect pathogens has been an attractive alternative to the application of chemical pesticides $^{2-3}$. Indeed, traditional pesticides not only damage the environment, but also trigger to the development of resistance by the pests. Often, they are harmful for other organisms together with the target pest. Therefore, the biological control by insect pathogens is a growing interest of research from the view of environmental concerns ${ }^{1}$. As an alternative, Gram positive Bacillus thuringiensis (Bt) subspecies, which produce insecticidal ä-endotoxin (crystal protein), have been widely used as biopesticide in agriculture ${ }^{4}$. However, to the best of our knowledge, there is no report on broad based and target-oriented study on Bt mass production in Bangladesh. This study focused on the large scale production and application of $B t$ biopesticide in Bangladesh agriculture from locally available cheap raw materials. The cost of raw materials for the production of $\mathrm{Bt}$ production is considerably higher. Depending on the plant production capacity, such cost varies from 30 to $40 \%$ of the total cost in the conventional Bt production process ${ }^{5}$. Therefore, the production of this insecticide in developing countries like Bangladesh is largely depended on the cost and the production media made from locally available sources including agroindustrial by-products. During the course of our study, efforts were made to use defatted mustard-seed meal (oil-cake), one of the most common by-products of edible oil industry in Bangladesh, as a raw material for the production of $B t$ toxin from the reference strain Bacillus thuringiensis subsp. kurstaki HD-73 and two local isolates of Bt. The growth pattern and toxin production of these organisms in the medium formulated from oil-cake was investigated and the efficiency of toxin production by the two local isolates was compared with the reference strain to find out a more potential toxin producing strain.

*Corresponding Author:

M Mozammel Hoq, Department of Microbiology, University of Dhaka, Dhaka-1000, Bangladesh.

E-mail:mhoq@univdhaka.edu 


\section{Materials and Methods}

\section{Microorganism and Growth Medium}

The international reference standard of Bacillus thuringiensis subsp. kurstaki HD-73 was obtained from Okayama University, Japan. Two local isolates, Bt- Soil-47 and Bt-Insect-1i, were isolated and characterized by us in the Enzyme and Fermentation Laboratory at the University of Dhaka. The growth medium was prepared by the published method described by Gangurde and Shethna 6 .

\section{Preparation of seed culture}

A loopful of bacteria from the stock culture was streaked onto a sterile nutrient agar plate, incubated at $30^{\circ} \mathrm{C}$ for $24 \mathrm{~h}$. A single colony was inoculated into $50 \mathrm{~mL}$ medium in a $250 \mathrm{~mL}$ flask and incubated in a shaker (N-Biotek, Model: NB-205VL, Korea) at $180 \mathrm{rev} / \mathrm{min}$ for $24 \mathrm{~h}$ at the temperature of $30^{\circ} \mathrm{C}$.

\section{Fermentation}

Batch fermentation was carried out for the study and each experiment was repeated twice under the similar conditions. Five milliliter of inoculums from the seed culture was transferred to $120 \mathrm{~mL}$ medium in a $500 \mathrm{~mL}$ flask and the mixture was incubated under the same conditions for $72 \mathrm{~h}$.

\section{Analysis of Samples}

Samples were collected aseptically in a Laminar air flow at $6 \mathrm{~h}$ intervals up to the end of the fermentation for study.

\section{Microscopic Studies}

The presence of spore and crystal protein was recorded at various growth stages by Phase contrast microscopy (Model: Primo Star, Carl Zeiss, Germany).

\section{Total Viable Cell Counts and Spore Counts}

Total viable counts were determined by spread plate method using nutrient agar plate. For spore counts, cultures were first heatshocked at $80^{\circ} \mathrm{C}$ for $20 \mathrm{~min}$ and then inoculated. Plating for each count was performed in duplicate.

\section{Estimation of Total Crystal Protein}

Routine estimation of total crystal protein was carried out by determining the net alkali soluble protein (ASP) content of the samples $^{7}$. Total crystal protein was determined by Lowry method ${ }^{8}$.

\section{Recovery and Analysis of Spore-Crystal Complex}

Spore-crystal complex was recovered as a dry powder using the acetone co-precipitation method ${ }^{9}$. Separate flasks were inoculated for each organism and the incubated flasks were harvested until sporulation and cell lyses were almost completed, generally after $72 \mathrm{~h}$ of fermentation. Endotoxin content of spore-crystal complex was determined by estimating the net alkali soluble protein (ASP) content by Lowry method ${ }^{7,8}$. In a typical experiment, 0.01 gm of spore-crystal powder was added to $1 \mathrm{~mL}$ of $0.1 \mathrm{~N} \mathrm{NaOH}$ solution and the mixture was vortexed well for 3 min with a vortex mixer and centrifuged for $10 \mathrm{~min}$ at $10,000 \mathrm{rpm}$. The supernatant containing dissolved crystal protein was used in the total crystal protein analysis. Spore-crystal powder collected from two local isolates was compared with the spore-crystal of the reference strain by SDS-PAGE. For this purpose, 0.05 gm of spore-crystal powder was added to $1 \mathrm{~mL}$ of $0.1 \mathrm{~N} \mathrm{NaOH}$ solution and the mixture was vortexed well for 3 min with a vortex mixer and then centrifuged for $10 \mathrm{~min}$ at 10,000 rpm. The supernatant containing dissolved crystal protein was used for SDS-PAGE analysis.

\section{Results}

\section{Microscopy}

Presence of spore and crystal protein formed by the $B t$ isolates were observed by Phase contrast microscope throughout the fermentation period and their pattern of spore and crystal formation were recorded as shown in Figure 1.

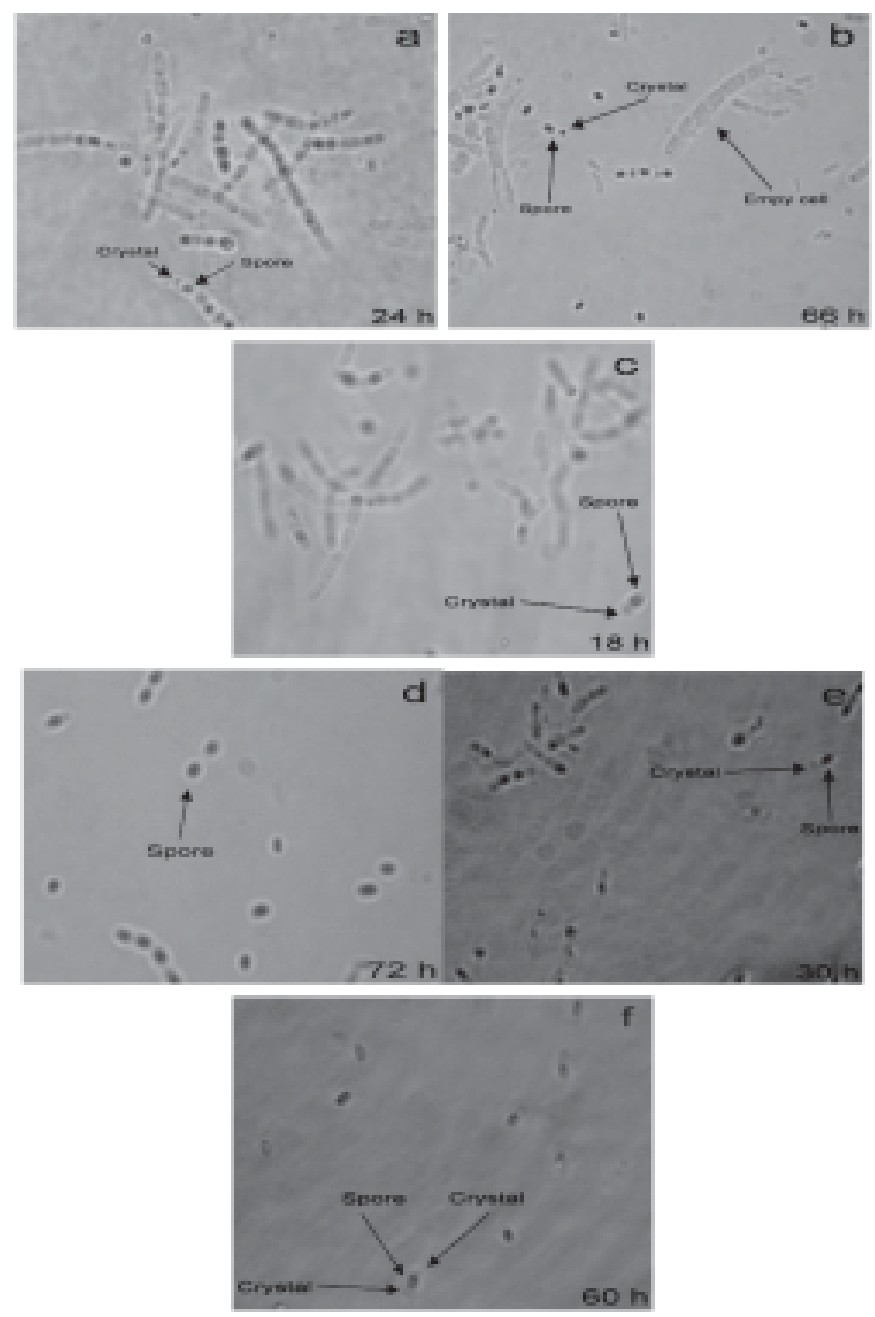

Fig 1: Photomicrograph of the Bt isolates showing spore-crystal complex and dissociated spores and crystals. a) B. thuringiensis subsp. kurstaki HD-73 (24h); b) B. thuringiensis subsp. kurstaki HD-73 (66h); c) B. thuringiensis (Isolate Soil-47) (18 h); d) B. thuringiensis; (Isolate Soil-47) (72 h); e) B. thuringiensis (Isolate Insect-1i) (30 h); f) B. thuringiensis (Isolate Insect-1i) (60 h). 


\section{Growth, sporulation and ä-endotoxin production}

Growth, sporulation and endotoxin production by the $B t$ isolates were estimated following the methods as described earlier at every $6 \mathrm{~h}$ interval during fermentation. The results are shown in Figure 2.
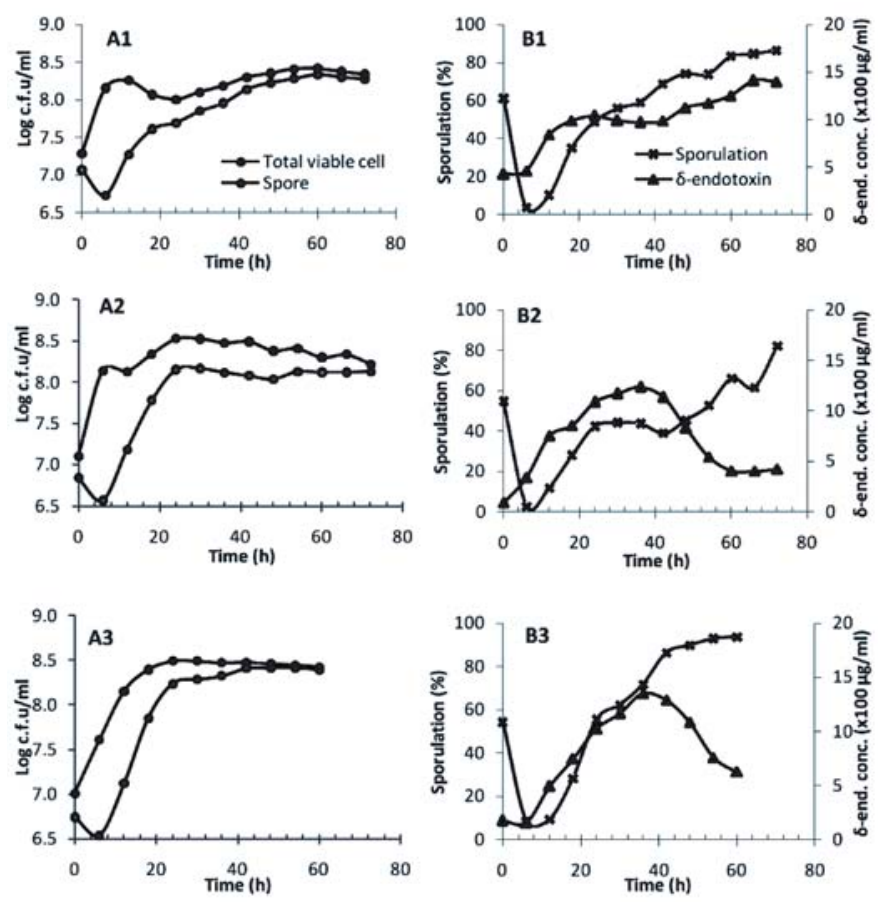

Fig 2: Time Course of growth (A1, A2, A3), sporulation and $\delta$ endotoxin production (B1, B2, B3) of the Bt isolates. $1=B$. thuringiensis subsp. kurstaki HD-73, 2. = B. thuringiensis (Isolate Soil-47); 3 = B. thuringiensis (Isolate Insect-1i)

Rate of endotoxin production and endotoxin content of sporecrystal complex

The rate of endotoxin formation by the organisms was calculated by estimating the highest endotoxin concentration in the medium (by Lowry Method ${ }^{6}$ ) and the time required to reach this level. The highest endotoxin concentration was recorded at $66 \mathrm{~h}$ for the reference strain and at $36 \mathrm{~h}$ for the both local isolates. At the end of fermentation, protein content of recovered spore-crystal complex of each organism was determined according to the procedure, described earlier.

Table 1: Rate of endotoxin fermentation and percentage of crystal protein in spore-crystal complex of Btk HD-73 and local isolates

\begin{tabular}{lccc}
\hline Bt isolate & $\begin{array}{c}\text { Maximum endotoxin } \\
\text { formation }(\mu \mathrm{g} / \mathrm{mL})\end{array}$ & $\begin{array}{c}\text { Productivity of } \\
\text { endotoxin }(\mathrm{g} / \mathrm{L} / \mathrm{h})\end{array}$ & $\begin{array}{c}\text { Crystal protein } \\
(\delta \text {-endotoxin }) \%\end{array}$ \\
\hline Btk HD-73 & 1410.61 & $21.37 \times 10^{-3}$ & 11.73 \\
Bt-Soil-47 & 1234.85 & $34.30 \times 10^{-3}$ & 8.24 \\
Bt- Insect-1i & 1350.00 & $37.50 \times 10^{-3}$ & 12.32 \\
\hline
\end{tabular}

\section{SDS-PAGE analysis of endotoxin of spore-crystal complex}

Protein profiles of endotoxin of spore-crystal complex recovered from the three organisms were analyzed by SDS-PAGE according to the above-mentioned procedure.

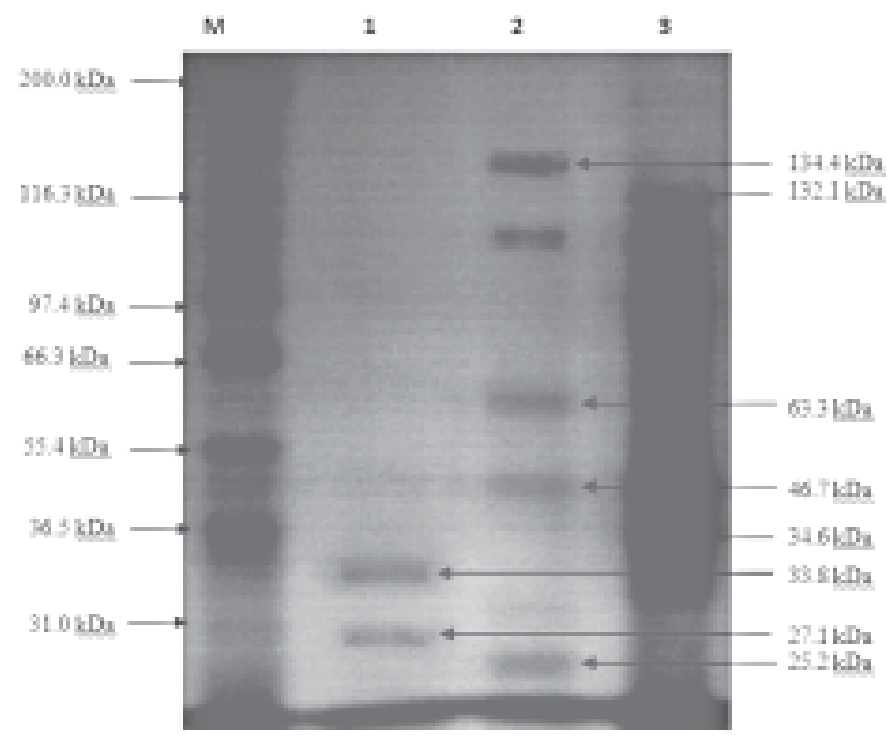

Fig 3: SDS-PAGE analysis of endotoxin of spore-crystal complex.


Isolate Insect-1i, Lane 2: Btk HD-73, Lane 3: Isolate Soil-47. Values next to arrow in the figure are approximate molecular weight of protein band in $k D a$.

\section{Discussion}

\section{Microscopic observation}

As we observed, the reference strain did not show any discernible spore till $18 \mathrm{~h}$ of fermentation. As shown in Figure 1a, both spores and crystals were started to form inside cells after 24h of fermentation, and a gradual increase in the release of spore-crystal complex was observed. From 60 to $72 \mathrm{~h}$ of fermentation, the cells began to lyse and the highest number of spore-crystal complex was excreted in the medium. According to our observation, the majority the crystals were attached with spore, although some were found to be dissociated from spore. Isolate soil-47 and Insect-1i showed the similar pattern as the reference strain. However, for the former cases, cells began to lyse much earlier (at $36 \mathrm{~h}$ ) than that for the reference strain (after $60 \mathrm{~h}$ ), releasing numerous spore-crystal complex in the fermentation medium. This growth pattern of the indigenous isolates is indicative of cost-effective fermentation process obviating the necessity to continue the fermentation process up to 72 hours unlike the case of reference strain. Unlike the spore-crystal complex of reference strain, crystals from both the isolates were no longer associated with spores after $40 \mathrm{~h}$ of fermentation (Figure 1:c-f.). Therefore, it is clear that the fermentation process can be terminated earlier around $40 \mathrm{~h}$, resulting into the maximum yield of spore-crystal complex. 


\section{Total viable cell and spore count}

All the three organisms investigated in this study showed some common patterns of growth. They showed no lag phase during the growth (Figure 2. A1, A2, A3). It might be related to the seed preparation $^{6}$. In our study, the seed was prepared in such a way that a step-by-step transfer of the organisms from small to large amount of fermentation medium, made the organisms familiar with the medium. When inoculums were added to the medium, they were already in exponential (log) phase. Since the short log phase saves time, therefore, from the view of saving time and cost effectiveness, such conditions could be favorable for large scale cultivation of the organism.

Another similarity of the organisms was that spore count was found to be less around $6 \mathrm{~h}$ than that of start of inoculation (Figure 2. A1, A2, A3). This is because preexisting spores in the seed gave higher spore count at the beginning of cultivation (just after inoculation). Over the time, these spores germinated giving the higher total viable count and lower spore count by 6 h. As a result, the total viable and cell count increased gradually. In case of the reference strain, there was no significance increase of viable cell and spore count after $48 \mathrm{~h}$. On the other hand, viable cell and spore counts of the indigenous isolates became almost saturated after $24 \mathrm{~h}$ of fermentation, suggesting that these isolates grow faster than the reference strain.

\section{$\delta$-endotoxin production}

For the isolate Soil-47, the highest $\delta$-endotoxin concentration $(1234.85 \mu \mathrm{g} / \mathrm{mL})$ was recorded at $36 \mathrm{~h}$ but the concentration was gradually decreased at the end of fermentation, although the degree of sporulation was found to increase (Figure 2. B2). Almost the same pattern was observed for the isolate Insect-1 $i$ while the highest $\delta$-endotoxin concentration $(1350 \mu \mathrm{g} / \mathrm{mL})$ was also recorded at $36 \mathrm{~h}$ (Firure 2. B3). After this time, the concentration was again gradually decreased. But Gangurde and Shethna ${ }^{6}$ showed that toxicity ( $\delta$-endotoxin formation) of $B$. thuringiensis is proportional with the degree of sporulation. This is agreed with the reference strain in the current study (Figure 2. B1) while the indigenous isolates showed deviations.

The endotoxin concentration by the two isolates was significantly decreased after $72 \mathrm{~h}$, exhibiting the maximum at $36 \mathrm{~h}$, the reason is not clear. The concentration of $\delta$-endotoxin in the medium was supposed to remain constant as the organism did not produce any toxin at that point. A careful microscopic observation of the two isolates indicates (Figure 1d and 1f) that spore-crystal complexes of both isolates began to dissociate after $36 \mathrm{~h}$ of fermentation and only a few spore-crystal complexes remained attached to each other till the end of the fermentation. In the current study, the estimation strategy for $\delta$-endotoxin was such that the crystal-toxin had to be attached with the spore to pellet during the centrifugation ${ }^{7,8}$. Since the large portion of $\delta$-endotoxin of the two isolates dissociated from spore, they were not pelleted with spore resulting into a decrease of estimation. Productivity of endotoxin of both the local isolates was greater than that of the reference strain (Table 1). This characteristic of the isolates suggests that they could be potential as efficient $B t$ toxin producers.

\section{Endotoxin content of spore-crystal complex}

The net content of crystal protein ( $\delta$-endotoxin) of the sporecrystal complex of the reference strain was estimated as $11.73 \%$ (Table 1). Although spore-crystal complex was dissociated and concentration of $\delta$-endotoxin was decreased; as noted before, spore-crystal complex of the isolate, Insect- $1 i$, contained higher percentage of $\delta$-endotoxin (12.32\%). Therefore, this isolate seems to be promising as an efficient toxin producer.

\section{Protein profile of endotoxin}

Alkali extract of spore-crystal complex of the reference strain (B. thuringiensis subsp. kurstaki HD-73) showed bands of 134.4, 63.3, 46.7 and $25.2 \mathrm{kDa}$ (Figure 3). According to the literature review by Höfte and Whiteley ${ }^{10}$, $\delta$-endotoxin of $B$. thuringiensis subsp. kurstaki (Btk) HD-3 comprises five different polypeptides, three Cry1 and two Cry2 protoxins, thus the expected protein bands from the organism are around 125-138 and 65-75 kDa. In our case, two additional bands (46.7 and $25.2 \mathrm{kDa}$ ) were observed which might be due to the strategic limitation of the experimental protocol or the impurity during the preparation of sample.

The isolate Soil-47 showed distinct bands of 132.1 and $34.6 \mathrm{kDa}$. The band of $32.1 \mathrm{kDa}$ protein could arise from the type cry1 and/or cry4 gene while the other ( $34.6 \mathrm{kDa})$ protein is possibly from the type cyt gene ${ }^{10}$. These experimental results suggest that the spore-crystal produced by the local isolates is $\delta$-endotoxin.

\section{Conclusion}

The present study was designed to employ the de-fatted mustard seed-meal as a raw material and to compare the efficiency and pattern of $\delta$-endotoxin production in the formulated medium by two locally isolated $B$. thuringiensis (Soil-47 and Insect-1i) with respect to the reference strain $B$. thuringiensis subsp. kurstaki HD-73. The formulated medium successfully supported the requirements for the growth and toxin production by the bacilli. Unlike the reference strain (B. thuringiensis subsp. kurstaki HD73) which can be harvested after 72 h of fermentation, fermentation beer of both of the local isolate should be harvested earlier between 36-42 h of fermentation to recover maximum effective spore-crystal complex. The present study is a promising basis for large scale production of biopesticide in Bangladesh. The local isolates, Soil-47 and Insect-1i can be potential and efficient sources of biopesticide productiion.

\section{Acknowledgement}

The authors gratefully acknowledge the partial financial support under special allocation program by Ministry of Science and Information \& Communication Technology (FY-2008-2009). We also acknowledge the grant from USDA through Ministry of Education for continuation of the related research project. 


\section{References}

1. Massaoud M K, Marokházi J, Fodor A, Venekei I. 2010. Proteolytic Enzyme Production by Strains of the Insect Pathogen Xenorhabdus and Characterization of an Early-Log-Phase-Secreted Protease as a Potential Virulence Factor. Appl Environ Microbiol , 6901-6909.

2. Ciche T A., Ensign J C. 2003. For the insect pathogen Photorhabdus luminescens, which end of a nematode is out? Appl Environ Microbiol. 1890-1897.

3. Glazer A N, Nikaido H. Microbial insecticides, In: Microbial Biotechnology Fundamentals of Applied Microbiology, (W.H. Freeman and Company, New York), 1995, 209-229.

4. Crickmore N, Zeigler D R, Feitelson J E, Schnepf J, Van Rie D, Lereclus J, Baum, and. Dean D H. 1998. Revison of nomenclature for the Bacillus thuringiensis pesticidal crystal proteins. Microbiol Mol Biol Rev. 62: 807-813.
5. Ejiofore A O, 1991. Production of Bacillus thuringiensis serotype H-14 as bioinsecticides using a mixture of spent brewer's yeast and waste cassava starch as the fermentation medium. Disc Innovation. 3: 85-88.

6. Gangurde R P and Shethna Y I. 1995. Growth, sporulation and toxin production by Bacillus thuringiensis subsp. israelensis and B. sphaericus in media based on mustard-seed meal. World J Microbiol Biotech. 11: 202-205.

7. Liu W M, Bajpai R, Bihari V 1994. High-density Cultivation of Sporeformers. Ann N Y Acad Sci. 721: 310-325.

8. Lowry O H, Rosebrough N J, Farr A L, and Randall R J. 1951. Protein measurement with the Folin phenol reagent. J Biol Chem. 193: 265-275.

9. Dulmage H T. 1970. Production of the spore- $\delta$-endotoxin complex by variants of Bacillus thuringiensis in two fermentation media. J Invertebr Pathol. 16: 385-389.

10. Höfte H, and Whiteley H R. 1968. Insecticidal crystal proteins of Bacillus thuringiensis, Microbiological Reviews. 53: 242-255. 